\title{
The Lifestyle of Breastfeeding Mother, Based on the Teaching of Avicenna (Ibn Sina)
}

\author{
Review Article
}

\section{Malihe Tabarrai $^{1}$, Fateme Nejatbakhsh ${ }^{1}$, Mahdi Hojati Moghadam ${ }^{2}$, Fateme Mohamadi Sorme ${ }^{1^{*}}$}

\author{
1. Department of Traditional Medicine, School of Persian Medicine, Tehran University of Medical Science \\ (TUMS), Tehran, Iran \\ 2. General Physician, Tehran, Iran
}

\begin{abstract}
Background: Breast-feeding is considered a global standard. Certainly special strategies have an important role in mother's success in exclusive feeding of the neonate and preservation of the mother's health. Healthy lifestyle in mothers can be one of the most effective measures to achieve this success. Unfortunately, due to the great attention to the growth and nutrition of the child in the first year of birth, mother's life style is neglected during lactation. Considering the widespread acceptance and interest in complementary medicine, it seems logical to search in Persian Medicine documents to find a guideline regarding the proposed issue. In Persian Traditional Medicine, a lot of attention has been paid to the lifestyle for all lifetimes, including lactation. In the present study, the views of Avicenna -renowned Iranian scientist- were discussed about the life style of mothers during lactation. Material and Methods: In this study, Al-Qanun $f i$ al-tibb by Avicenna $\left(11^{\text {th }}\right)$ and for thorough discussion also reviewed the views of a later Iranian scientist, Kholase al-hekma by Mohammad Hossein Aghili Alavi Khorasani $\left(18^{\text {th }}\right)$ were studied to collect all of information about life style of mothers during lactation. Furthermore, a search in PubMed, Scopus, Google Scholar, Sid, Iran doc was done to get related data about this field from 1990-Jan-1 to 2018-Dec-30. Conclusion: Healthy lifestyle during lactation has six main axes. These six axes include air, nutrition, physical activity and massage, sleep and wakefulness, evacuation of harmful substances and maintaining essential ingredients, and psychic movement and repose. In order to the mother would be able to produce adequate milk for the infant and her health would be preserved.
\end{abstract}

Keywords: Breastfeeding, Complementary Medicine, Persian Medicine, Iranian Traditional Medicine, Lifestyle.

\section{Introduction}

In the past, Persian Medicine physicians had great experiences about pregnancy and breast-feeding. Persian Medicine has a history of more than 8000 years $(1,2)$. Iranian Traditional Medicine refers to a set of all knowledge and actions used in diseases from the distant past up to the present, which has transferred based on practical experience and observations from one generation to another (3). According to this medicine, the most important principle is prevention from diseases rather than their treatment (4). The physician should help the people to remain healthy, and if they became ill, then treat them (5). Therefore, in this view, lifestyle adjustment is one of the most important health issues. Even in the treatment of diseases, lifestyle modification is on the first line (6) .

Breast-feeding is considered a global standard (7). Definitely the mother's success in exclusive feeding of the neonate and preservation of the mother's health need special measures. Nevertheless, concerning

*Corresponding Author:

Fateme Mohamadi Sorme,

$\mathrm{PhD}$ candidate of Traditional Medicine,

Department of Traditional Medicine, School of Persian Medicine (TUMS),

Tehran University of Medical Science, Tehran, Iran.

Email: fatememohamadisorme@yahoo.com the limitations in drug prescription during this period and the effect of lifestyle on the mother and child's health, it is great importance to have a healthy lifestyle. However, very few studies have been done on mother's lifestyle during breast-feeding. Persian Medicine has developed a special life style for the mother to have adequate milk and to maintain her own health.

Thus, the present study was conducted to investigate the opinions of prominent figures about lifestyle of mother during lactation in Persian Medicine such as Avicenna (Ibn Sina) that mentioned in his great book called Al-Qanun Fi al-Tibb. Avicenna lived in $10^{\text {th }}$ and $11^{\text {th }}$ centuries (980-1037 AD), whose Al-Qanun Fi al-Tibb book is known as the reference of Persian Medicine $(8,9)$. It was translated to Latin language in $12^{\text {th }}$ century and was taught in the Europe until the $17^{\text {th }}$ century (1).

\section{Material and Methods}

In this narrative review study, Al-Qanun fi altibb by Avicenna $\left(11^{\text {th }}\right)$ was studied and for thorough discussion also reviewed the views of a later Iranian scientist who would benefit from the latest experiences of Iranian medical scientists. Kholase al-hekma by Mohammad Hossein Aghili Alavi Khorasani $\left(18^{\text {th }}\right)$. Then all the contents about life style of the mother during lactation were collected. Furthermore, a search in PubMed, Scopus, Google Scholar, Sid, Irandoc, 
Iranmedex was done to get related data about this field from 1990-Jan-1 to 2018-Dec-30. The key words of search were breastfeeding and lactation and related terms.

\section{Result}

In Persian Medicine, healthy lifestyle is adjusted for everyone considering six main axes and through modifying them. These six axes include air, nutrition, physical activity and massage, sleep and wakefulness, evacuation of harmful substances and maintaining essential ingredients, psychic movement and repose (5, 10). Under special conditions such as pregnancy, breastfeeding, childhood, and senescence, special recommendations may be added in each of these axes, thereby providing a healthier lifestyle for the group of interest. Thus, recommendations of Persian Medicine regarding modifying the lifestyle during breast-feeding period are stated further in the form of the mentioned six axes.

\section{1-Air:}

According to Persian Medicine, and as a general principle in health, a clean air and free of contamination causes health of the person and will improve his organs such as the heart and brain.

Mixing the air with dust, vapor, and other pollutants, will adversely affect the health $(1,11)$.

\section{2- Nutrition:}

Attention to nutrition has been one of the most important issues in the Persian Medicine. The quality of nutrition and type of food plays a significant role in the Persian Medicine (12). In this viewpoint, with respect to the breast-feeding period, the recommendations are categorized into two parts:

(A) General orders of nutrition in all individuals even lactating mothers

It is necessary to use high quality foods and avoid of pastry food. Using a variety of food pyramid groups is essential for health. People should not eat until they feel hungry, and should stop eating before feeling completely full. The food should be well-chewed to completely mix with saliva $(11,13)$.

(B) The food recommendations and specific orders to the breast-feeding period

Persian Medicine considers blood as the precursor for milk production. Blood is converted to milk after passing through glandular tissues of the breast. Thus, the foods producing high quality of blood are very suitable for milk production for example lamb, milk (14).

Iranian Traditional Medicine has emphasized on consumption of moderate amounts of food that are suitable for stomach and are well digested (2). In this viewpoint, in addition to emphasis on the consumption of all nutritional groups during the breast-feeding period, the best foods that should be consumed in the mothers diet in all food subgroups are listed in table 1:

Table 1: The food groups of the mother's diet.

\begin{tabular}{|c|c|}
\hline Food groups & \\
\hline \multirow[t]{2}{*}{ Fruit and vegetable } & Fruits: grapes, pomegranate, sweet apple, konar (Fruit of Cedar tree), dates, and raisin \\
\hline & Vegetables: spinach, lettuce, carrots, turnip \\
\hline Dairies & $\begin{array}{l}\text { fresh cheese, rice pudding (A food made up of rice cooked in water and milk sweetened } \\
\text { with little amounts of cardamom and rosewater), kheer (similar to rice pudding, but in- } \\
\text { stead of rice, rice flour is used) }\end{array}$ \\
\hline \multirow[t]{3}{*}{ Meat and Beans } & $\begin{array}{l}\text { Meat: fresh fish, lamb meat, mutton meat, goat pup meat, calf meat, pigeon meat, par- } \\
\text { tridge meat, one-year lamb meat extract, chicken meat, partridge meat, biddy meat juice } \\
\text { (ma-ol-lahm), soft-boiled egg. }\end{array}$ \\
\hline & Beans: corn, mung bean \\
\hline & Nuts: almond, hazelnut, sesame \\
\hline Bread and Cereals & Wheat, rice, bread baked with good wheat \\
\hline Further & $\begin{array}{l}\text { Grape juice, honey syrup } \\
\text { And use of a kind of soup which is a mix of soft far materials and soft meats such as } \\
\text { chicken, goat, lamb, spinach, legumes, squash, rice, pearled barley, coriander, cooked } \\
\text { together }(2,15)\end{array}$ \\
\hline
\end{tabular}

In addition to useful food recommendations, consumption of several foods has not been recommended due to change the quality of milk. These foods include: Stale calf meat, old animal meat, stale fish or cured fish, mustard, mint, basil, and garden cress (11).

\section{3- Physical Activity and Massage:} this (11).

Among the six principles of health protection, Avicenna considers exercise as the most important measure for

Moderate exercise is among the recommendations of Iranian Traditional Medicine for the breast-feeding period. This can increase the milk in mothers. In this period, excessive and extreme exercises are not recommended 
(11). Moderate activity means an exercise that is not too much; rather it is heavy enough to slightly heat the skin and makes it red (16).

Furthermore, according to Persian Medicine, many of the mother's physical activities while taking care of children are useful for their health, including walking, carrying the baby, washing them, raising them and gently massaging them. Hand movements are more suitable for breast-feeding mothers than other movements, and walking alongside the baby's carriage is the most useful movement (17).

Gentle massage has also been recommended during this period because increase the milk (11).

\section{4- Evacuation of harmful substances and maintaining essential ingredients:}

Waste materials as urine, sweat and stool are produced in the body on a daily basis, which should be discharged off the body through their devised ways. In Persian Medicine, this is called as depletion or evacuation of harmful substances or body's action of getting rid of the wastes (11)(11). If the waste materials are not well disposed, their toxins will be attracted and change the quality of the milk. Therefore, the physician's role is to help with the removal of these materials, such as the elimination of constipation (11).

In breast-feeding period, mild bathing with semiwarm water has been recommended to these mothers. Long stay in bathroom is not recommended due to degradation and shrinkage of milk (16). Accordingly, use of sauna, Jacuzzi, and bathing with very hot or cold water is not suitable.

In this viewpoint, intercourse is also limited (11), as it is considered one of the reasons of changes in the mother's milk and reduction of its quality.

\section{5- Sleep and Wakefulness:}

Balanced sleep is considered one of the health factors in Iranian Traditional Medicine. Sleep help the food to be digested completely and change into blood (1). In Persian Medicine, blood is considered the precursor for milk (14). Thus, balanced sleep, as a factor influencing the blood production, can cause moderate milk production.

Sleep should be proportionate, moderate, and at proper time. Both little and too much sleep can cause changes in the brains function. Low sleep results in weakness, while oversleeping causes psychological dullness and heaviness in the head (1).

Normal sleep should have several characteristics. The best time of sleeping is at night and after emptying stomach from food, i.e. at least two hours after eating. It should be deep and continuous and preferably on the right side. One should not sleep under direct light of moon or sunlight, and the body should be covered by a coverlet at the time of sleeping (18).

\section{6- Psychic Movement and Repose:}

In viewpoint of Persian Medicine, all psychological states such as happiness, sorrow, hope, and anger effect on health $(5,11)$. Recommending for being happy and happiness in life and experiencing no excessive sadness over unpleasant events are among the principles of keeping health in Persian Medicine.

Out of balance extent of these emotions results in impaired normal body function and development of disease. The importance of psychological states in Persian Medicine is such that, its scientists believe that human body is mostly affected by psychological states rather than by physical factor (1).

Accordingly, in this viewpoint, it has been greatly emphasized that no suffering or difficulty should occur for the mother during the breast-feeding period $(11,16)$, as psychological turmoil such as extreme anger results in shrinkage or breakdown of secretion of mother's milk (19).

\section{Discussion}

In Iranian Traditional Medicine, lifestyle is the most important part in the prevention of diseases . Iranian practitioner considers clean and healthy air as an essential component for health keeping. In this regard, although there is no study directly investigated the effect of clean air or pollutants on breast-feeding, it has been shown that exposure to high levels of sulfur dioxide $\left(\mathrm{SO}_{2}\right)$ and Total Suspended Particular (TSP) pollutants during the first month of pregnancy is associated with the increased risk of fetal loss and low birth weight (20).

Paying attention to the mother's nutritional model and presenting a clear and practical pattern of nutrition for the mother has been among the interesting points made by Avicenna. This pattern is based on consuming all nutritional groups, where in each food group; special foods are introduced and recommended for supplying the needs of breast-feeding mothers. This nutritional model corresponds to any food pyramid available in today's nutrition. Use of food pyramid as a simple and comprehensible method for breast-feeding mothers requires no special skill or instrument, and can be easily trained to the mothers (21).

In the first thousand days (initiation of pregnancy up to the two-year breast-feeding period), the mother's nutrition should be based on consuming large amounts of nutrient-rich foods (22). The smart recommendation of Persian Medicine includes consumption of almond, hazelnut, pistachio, and wheat which are among rich foods, highlighting the greater necessity of paying attention to the recommendations of this old medicine (23). Previous studies conducted in Iran showed that, these foods are more specific to lactation than other foods and increase the amount of milk (24). Thus, further studies are suggested to be conducted on the effect of consumption on lactation.

Today, micronutrients and consumption of supplements in the mother's diet have attracted a great deal of attention. However, due to the overdose possibility regarding consumption of supplements, food consumption seems to be very safe for supplying the micronutrients (25).

As today there is limited evidence on nutritional needs of mothers during breast-feeding period (25), therefore, there is no adequate information on the food pattern of breast-feeding mothers (26). Even sparse studies suggest improper nutritional pattern of breast- 
feeding women (27). Further research should be conducted in this regard. Meanwhile, research on the pyramid pattern of nutrition as noted by Persian Medicine physicians can be effective.

In Persian Medicine, in addition to recommending the use of many useful foods, avoiding of some foods during breast-feeding period has been recommended. This may be due to changes in taste or volume of milk (24). Different studies have also prohibited consumption of some foods for breast-feeding mothers. Goun Jeong et al. stated that during the breast-feeding period, the mother should avoid consuming foods to which the child shows negative reaction (28).

Also, Susana et al. believed that the mother should have a various diet including all food groups. However, during the breast-feeding period, they should reduce and possibly avoid consumption of alcohol, tobacco smoking, and caffeine drinks (25). Mothers who used alcoholic beverages during the pregnancy had a lower level of zinc, copper, and iron in their milk (29).

Avicenna has been recommended that, the mother should have moderate physical activity and avoid performing heavy exercise as well as heavy strains and suffering. In addition, some Iranian medical scholars more accurately state that upper limbs exercises have been considered to be more suitable for lactation period (17). In Dewey et al. study was shown the moderate exercise had no adverse effect on the breast-feeding and it clearly resulted in improved cardiovascular function (30). It is recommended to investigate the effect of upper limbs exercises as well as their success in persistence of breast-feeding. Persian Medicine physicians have recommended gentle and mild massage for breast-feeding period. Saatsaz et al. in a clinical study found that, gentle massage as an adjuvant therapy is effective for mitigation of pain, anxiety, and stress in mothers (31). However, the effect of massage on the quality or quantity of milk was not evaluated in this study.

Sufficient sleep and rest of mothers is a key principle among the six principles of keeping health. As mentioned in Al-Qanun fi al-tibb, mother's insomnia is one of the reasons for shrinkage of milk secretion and dilution of its consistency. Breast-feeding mothers have been recommended to sleep more $(11,16)$. There is no paper investigated the role of sleep during breastfeeding period. However, as mentioned in the chapter of breast-feeding in Krause's book that is a text book of nutrition, entitled as, adequate rest of the mother is considered as a key factor for adequate milk production (32).

Psychological states are among the very important aspects in lifestyle. This part of the six principles of health keeping has been greatly noted in Folk medicine, where all acquaintances of the breast-feeding mother try to keep this mother away from sorrows, suffering, and bad news. During the breast-feeding period, the mother should be in complete peace and be absolutely away from any psychological suffering and hardship $(11,16)$. Oxytocin is one of the essential hormones for lactation that causes milk secretion (33). Stuebe et al. said in postpartum depression and anxiety, levels of oxytocin have decreased and causes lack of lactation and early weaning. Also, maternal mental/ emotional health disorders, is associated with a decrease in exclusive breastfeeding in the first 6 months (34). Thus Michael et al. in their study stated that, maternal factors such as stress and anxiety can decrease milk production (7).

\section{Conclusion}

Studying the history of medicine as well as accurately investigating the Al-Qanun Fi al-Tibb written by Avicenna suggested that, he was the first author to discuss about the lifestyle (1). Use of good and clean air, following a special diet for breast-feeding period, proportionate and moderate exercise as well as gentle massage for the mother, adequate sleep and rest, short baths, and reduction of physical and psychological stress for the mother are among the points recommended for breast-feeding mothers. Further, refusal of consuming stale foods such as stale calf meat, stale and cured fish meat, and meat of old animals, as well as vegetables such as mustard, basil, mint, and green cress, have been also recommended, as emphasized in the current studies.

Now, concerning the very important role of this period in the child's health and the special importance of being fed with mother's milk especially during the first six months of birth, as well as the extensive positive tendencies to alternative medicine, conducting more extensive and broader studies is essential in this regard.

\section{References}

1. Choopani R, Emtiazy M. The concept of lifestyle factors, based on the teaching of avicenna (ibn sina). International journal of preventive medicine. 2015;6:30.

2. Jafari-Dehkordi E, Mokaberinejad R, Minaei B, Sohrabvand F, Nazem E, Hashem Dabaghian F, et al. A Review of Pioneer Physicians' Work on Maternal Health in Pregnancy in Ancient Iran; Narrative Systematic Review. Iranian journal of public health. 2013;42(12):1340-6.

3. Rezaeizadeh H, Alizadeh M, Naseri M, Shams Ardakanie MR. Traditional Iranian Medicine Point of View on Health and Disease. Iranian journal of public health. 2009;38(1):169-72.

4. Zeinalian M, Eshaghi M, Hadian M, Naji H, Marandi SM, Asgary S. Eight Essential Foods in Iranian Traditional Medicine and their Role in Health Promotion and Well-being. International journal of preventive medicine. 2017;8:2.

5. Qaraaty M, Tabarrai M, Aliasl Mamaghani J, Ghorbanifar Z, Latifi M. The Role of the Iranian Traditional Medicine in the Development of Impoverished Areas in Iran. Advances in Environmental Biology. 2014;8(6):1564-8.

6. Tansaz M, Memarzadehzavareh $\mathrm{H}$, Qaraaty $\mathrm{M}$, Eftekhar T, Tabarrai M, Kamalinejad M. Menorrhagia Management in Iranian Traditional Medicine. Journal of evidence-based complementary \& alternative medicine. 2016;21(1):71-6.

7. Kominiarek MA, Rajan P. Nutrition Recommendations in Pregnancy and Lactation. The Medical clinics of North America. 2016;100(6):1199 -215 . 
8. Mokaberinejad R, Zafarghandi N, Bioos $\mathrm{S}$, Dabaghian FH, Naseri M, Kamalinejad M, et al. Mentha longifolia syrup in secondary amenorrhea: a double-blind, placebo-controlled, randomized trials. Daru : journal of Faculty of Pharmacy, Tehran University of Medical Sciences. 2012;20(1):97.

9. Tabarrai M, Niktabe Z, Masoudi N, Eftekhaar T. Avicenna's Point about Bladder Gas as a Cause of Interstitial Cystitis. Iranian journal of public health. 2018;47(9):1436-7.

10. Mansouri P, Khademi A, Pahlevan D, Memariani Z, Aliasl J, Shirbeigii L. Review of Medicinal Remedies on Hand Eczema Based on Iranian Traditional Medicine: A Narrative Review Article. Iranian journal of public health. 2016;45(8):986-96.

11. Avicenna. Al Qanun Fi al-Tibb. Beirut: Allaalami; 2005. 223-80 p.

12. Moradi H, Minaii B, Nikbakht Nasrabadi A, Siahpoosh MB. Avicenna Viewpoint about Health Preservation through Healthy Nutrition Principles. Iranian journal of public health. 2013;42(2):220-1.

13. Saifadini R, Tajadini H, Choopani R, Mehrabani M, Kamalinegad M, Haghdoost A. Perception of Alzheimer Disease in Iranian Traditional Medicine. Iranian Red Crescent medical journal. 2016;18 (3): 22054.

14. Ghorat F, Nejatbakhsh F, Ahmadi M, Namazi N. Effective Factors on Shortage of Breastfeeding According to Iranian Traditional Medicine. Iranian journal of medical sciences. 2016;41(3 Suppl):S29.

15. Aghili Khorasani MH. Makhzan-ol-Adviyah. Tehran: Tehran University of Medical Sciences; 2009. 143 p.

16. Aghili Khorasani MH. Kholase al- hekmah. Quom: Esmailian; 2006. 929-39 p.

17. Siahpoosh M. Exercise in Iranian Traditional Medicine. Tehran: Niakan; 2012.

18. Feyzabadi Z, Jafari F, Feizabadi PS, Ashayeri H, Esfahani MM, Badiee Aval S. Insomnia in Iranian traditional medicine. Iranian Red Crescent medical journal. 2014;16(3):e15981.

19. Bioos S. Healthy Pregnancy. Tehran: Almaee; 2015. $254 \mathrm{p}$.

20. Hou HY, Wang D, Zou XP, Yang ZH, Li TC, Chen YQ. Does ambient air pollutants increase the risk of fetal loss? A case-control study. Archives of gynecology and obstetrics. 2014;289(2):285-91.

21. Bashirian S, Jalily M, Barati M. Nutritional behaviors status and its related factors among pregnant women in Tabriz: A cross-sectional study. Pajouhan Scientific Journal. 2016;14(2):34-43.

22. Dewey KG. Reducing stunting by improving maternal, infant and young child nutrition in regions such as South Asia: evidence, challenges and opportunities. Maternal \& child nutrition. 2016;12 Suppl 1:27-38.
23. Gorji N, Moeini R, Memariani Z. Almond, hazelnut and walnut, three nuts for neuroprotection in Alzheimer's disease: A neuropharmacological review of their bioactive constituents. Pharmacological research. 2018;129:115-27.

24. Kabiri M, Kamalinejad M, Sohrabvand F, Bioos S, Babaeian M. Management of Breast Milk Oversupply in Traditional Persian Medicine. Journal of evidence-based complementary \& alternative medicine. 2017;22(4):1044-50.

25. Ares Segura S, Arena Ansotegui J, Diaz-Gomez NM. [The importance of maternal nutrition during breastfeeding: Do breastfeeding mothers need nutritional supplements?]. Anales de pediatria (Barcelona, Spain : 2003). 2016;84(6):347.e1-7.

26. Cuervo M, Sayon-Orea C, Santiago S, Martinez JA. Dietary and health profiles of Spanish women in preconception, pregnancy and lactation. Nutrients. 2014;6(10):4434-51.

27. Marangoni F, Cetin I, Verduci E, Canzone G, Giovannini M, Scollo P, et al. Maternal Diet and Nutrient Requirements in Pregnancy and Breastfeeding. An Italian Consensus Document. Nutrients. 2016;8(10).

28. Jeong G, Park SW, Lee YK, Ko SY, Shin SM. Maternal food restrictions during breastfeeding. Korean journal of pediatrics. 2017;60(3):70-6.

29. Choi YK, Kim JM, Lee JE, Cho MS, Kang BS, Choi $\mathrm{H}$, et al. Association of Maternal Diet With Zinc, Copper, and Iron Concentrations in Transitional Human Milk Produced by Korean Mothers. 2016;5 (1):15-25.

30. Dewey KG, Lovelady CA, Nommsen-Rivers LA, McCrory MA, Lonnerdal B. A randomized study of the effects of aerobic exercise by lactating women on breast-milk volume and composition. The New England journal of medicine. 1994;330(7):449-53.

31. Saatsaz S, Rezaei R, Alipour A, Beheshti Z. Massage as adjuvant therapy in the management of post-cesarean pain and anxiety: A randomized clinical trial. Complementary therapies in clinical practice. 2016;24:92-8.

32. Mahan LK, Raymond JL. Krause's food \& the nutrition care process. 14 ed: Elsevier; 2017.

33. Boutet C, Vercueil L, Schelstraete C, Buffin A, Legros JJ. [Oxytocin and maternal stress during the post-partum period]. Annales d'endocrinologie. 2006;67(3):214-23.

34. Stuebe AM, Grewen K, Meltzer-Brody S. Association between maternal mood and oxytocin response to breastfeeding. Journal of women's health (2002). 2013;22(4):352-61. 